\title{
Experimental study of the hydraulic jump on reverse bed with porous screens
}

\author{
A. Abbaspour ${ }^{1} \cdot$ T. Taghavianpour $^{1} \cdot$ H. Arvanaghi $^{1}$
}

Received: 15 January 2018 / Accepted: 4 September 2019 / Published online: 13 September 2019

(c) The Author(s) 2019

\begin{abstract}
Nowadays, the porous screens have been used extensively in open channels to prevent erosion in ditches as the water in supercritical state flows past the screen which forces the formation of a hydraulic jump upstream of the screen and produces significant energy loss. In this investigation, the operation of screens has been studied for supercritical flow and the Froude number in the range of 4.5 to 10.6 on two reverse slopes experimentally. In this study, the parameters included arrangements of screens in both the single and double types, and the angle and distance of screens from the hydraulic jump toe. The screens were studied with a porosity of about $50 \%$ with square holes. The study results showed that using of screens on the reverse slope of -0.025 dissipates more energy compared to reverse slope of -0.015 . The screens with double arrangement have better performance and dissipate more energy than the screens with single arrangement, while the distance of screens from the toe of the hydraulic jump does not have a significant effect on the energy dissipation.
\end{abstract}

Keywords Energy dissipation $\cdot$ Porous screens $\cdot$ Reverse slope $\cdot$ Sequent depth $\cdot$ Hydraulic jump

\section{Introduction}

A hydraulic jump occurs at the transition from supercritical flow to subcritical flow. It is characterized by a sudden increase in water depth and loss in the energy. The turbulent hydraulic jump is one of the significant problems in the hydraulic engineering.

The classical hydraulic jump is a basic phenomenon commonly used in stilling basins. In a hydraulic jump, the energy of flow is dissipated along the channel, resulting in a decrease in velocity and an increase in depth in the direction of flow. The subcritical sequent depth $y_{2}$ of a classical hydraulic jump, for the depth $y_{1}$ and mean velocity $u_{1}$ of the supercritical upstream flow of the jump, is obtained by the following equation (Vischer and Hager 1995):

$\frac{y_{2}^{*}}{y_{1}}=\frac{1}{2}\left(\sqrt{1+8 F r_{1}^{2}}-1\right)$

A. Abbaspour

akabbaspour@yahoo.com

1 Department of Water Engineering, University of Tabriz, Tabriz 516661647, Iran where $F r_{1}$ is the upstream flow Froude number at the beginning of the jump and $g$ is the acceleration due to gravity.

Pagliara and Peruginelli (2000) were studied hydraulic jumps formed on adverse slopes experimentally. A general equation, for the sequent depth ratio, was proposed and corroborated by experimental data. Hydraulic jumps in sloping channels have been studied by Beirami and Chamani (2006, 2010). In this paper, the roller length and energy loss of a large variety of hydraulic jumps were investigated in horizontal and sloping channels experimentally. A stilling basin with bottom slopes of $0.0,-0.025,-0.050,-0.075$, and -0.100 was used to generate the jumps. An empirical relationship is presented to predict the roller length.

Mudgal and Pani (2012) used sills to aid the formation of a hydraulic jump in a stilling basin. The drag force acting on a sill in forced hydraulic jump depends on the initial Froude number $F r_{1}$, the height of the sill $S$, and its distance from the toe of the jump. Farhoudi and Khalili Shayan (2013) have investigated the stability of free hydraulic jump on adverse stilling basins from a theoretical point of view. In this research, a theoretical equation for estimating the minimum upstream Froude number to establish the free hydraulic jump on an adverse bed was presented. The hydraulic characteristics of forced jump due to perforated sill were measured and compared with the classical hydraulic jump by 
Behrouzi-Rad et al. (2013). The experiments results of this study certified the effect of the perforated sill on dissipation of energy. Cherhabil and Debabeche (2016) have studied the hydraulic jump in a sloped trapezoidal channel experimentally. The study was done to determine the impact of channel slope on the characteristics of the jump. An experimental investigation is done to determine the relationships between the sequent depth ratio of the jump and the initial Froude number and the channel slope. An investigation of hydraulic jump in the stilling basins with stepped sills has been done experimentally by Minaei Gigloo et al. (2016). They found that the sill with two steps has better efficiency to stabilize a jump in the stilling basin compared to sill with three steps. Parsamehr et al. (2017) have investigated the characteristics of hydraulic jump, including sequent depth, relative length of the jump, and energy loss on rough bed with discontinuous roughness elements of lozenge shape over adverse slope. It was found that by increasing the height of roughness elements and steeping the adverse slope, the sequent depth ratio, and relative length of the jump decreased, while the energy loss increased.

In recent years, the screens have been applied to prohibit the erosion in roadside ditches and steep bed surfaces. This screen is placed perpendicularly across the supercritical flow in the ditch which forces the formation of a free or forced hydraulic jump upstream of the screen and produces significant energy loss. The experimental study showed that the porous screens with a porosity of about $40 \%$ were used as effective energy dissipaters in the stilling basins. The results of these experiments are presented by Rajaratnam and Hurtig (2000). The relative energy loss was considerably larger than that created the similar classical hydraulic jump, and the sequent depth required was observed about one half of $y_{2} *$.

Bozkus et al. (2007) and Bozkus and Aslankara (2008) evaluated the energy dissipation of the screen in a flume with horizontal bed. The experiments were done with Froude numbers 2.5 up to 8.5 , screen porosities of $40 \%$ and $50 \%$, and distances of double screens between 1 and $5 \mathrm{~cm}$ The experiments show the screen porosity of $40 \%$ provided higher energy dissipation. The screens with double arrangement with the imposed hydraulic jump dissipated more energy.

Shaker et al. (2013) studied the effect of holes shape in the screen wall on the efficiency of the energy dissipation. Three holes of different shapes were used in screen walls, circular, square and two different dimensions for each model, with a fixed porosity of $40 \%$. Sadeghfam et al. (2014) investigated the effectiveness of screens as the energy dissipaters in small hydraulic structures experimentally. In the experimental study, the experiments were done for a range of Froude numbers between 2.5 and 8.5 , screen porosity of $40 \%$ and $50 \%$, and gaps of double screens between 1 and $5 \mathrm{~cm}$. The screens with double arrangement with the imposed hydraulic jump dissipated more energy. Singh (2018) has conducted laboratory experiments on screens or porous baffles with a porosity of about $50-60 \%$. The single wall or double wall was used with the different angles at $45^{\circ}, 90^{\circ}$ and $135^{\circ}$. The experiments were done for a range of Froude numbers $\left(F r_{1}\right)$ from about 1.5 to 6 . The downstream flow was found to be supercritical flow and tail water depth after the screen is equal to the 0.79 times to $y_{2}$.

The objective of this research is to investigate the effect of single or double screens on the characteristics of a jump on a new type of stilling basin with adverse slope. This paper reports the results of a laboratory investigation on energy loss and the depth of jump, $y_{2}$, of both sill-controlled hydraulic jump and single and double screens on the smooth beds. Finally, this note is to offer theoretical and experimental results for the case of an end sill-controlled hydraulic jump on an adverse slope to estimate sequent depth and energy loss of jump. It is thought that the experiments conducted within the domain of this study (Bozkus et al. (2007), Bozkus and Aslankara (2008), Sadeghfam et al. (2014)) extended the information about porous screen on reverse bed stilling basins as the alternative energy dissipaters.

\section{Materials and methods}

\section{Theoretical background}

In general, hydraulic jump characteristics in a stilling being controlled by screens are dependent on fluid properties and hydraulic state of flow. The subcritical sequent depth $y_{2}$ may depend on the height of the sill, $s$; acceleration due to gravity, $g$; depth of upstream flow, $y_{1}$; the slope of the bed $(0.015$ and $0.025), S_{0}$; the angle of the screen, $\alpha$; average velocity, $V_{1}$, at the beginning of the jump, height of end sill $S$, the number of screens, $n$; the distance of the screen from beginning of the jump, $r$. Therefore, basic factors affecting the depth of the hydraulic jump are defined as:

$f_{1}\left(\rho, v, y_{1}, y_{2}, V_{1}, g, r, n, \alpha, s, S_{0}\right)=0$

Using the principles of dimensional analysis, the following relationship is obtained:

$f_{2}\left(\frac{y_{2}}{y_{1}}, F r_{1}=\frac{V_{1}}{\sqrt{g y_{1}}}, R e_{1}=\frac{V_{1} y_{1}}{v}, \frac{r}{y_{1}}, \frac{s}{y_{1}}, n, \alpha, S_{0}\right)=0$

where $F r_{1}$ is the approaching flow Froude number at the beginning of the jump and $R e_{1}$ is the Reynolds number based on $y_{1}$. The values of the Reynolds number $R e_{1}$ were in the range of 61,200-175,000. For high Reynolds number, viscous force effects can be omitted. Then, Eq. (3) becomes

$\frac{y_{2}}{y_{1}}=f_{3}\left(F r_{1}, \frac{r}{y_{1}}, \frac{s}{y_{1}}, n, \alpha, S_{0}\right)$. 
The energy loss in the hydraulic jump is calculated from the specific energy and continuity equations as follows:

$E_{\mathrm{L}}=E_{1}-E_{2}=\left(y_{1}+\frac{v_{1}^{2}}{2 g}\right)-\left(y_{2}+\frac{v_{2}^{2}}{2 g}\right)$.

Similarly, for relative energy loss of jump $\frac{E_{\mathrm{L}}}{E_{1}}$ using the Pi theorem the following relationship is also obtained:

$\frac{E_{\mathrm{L}}}{E_{1}}=f_{4}\left(F r_{1}, \frac{r}{y_{1}}, \frac{s}{y_{1}}, n, \alpha, S_{0}\right)$.

The experiments were conducted in a metal-glass flume with a rectangular cross section. The flume was $0.25 \mathrm{~m}$ wide, $0.5 \mathrm{~m}$ deep, and $10 \mathrm{~m}$ long. The bed slope of the channel was 0.002 , but the portion of the channel was with a slope of 0.015 and 0.025 for the length of $2 \mathrm{~m}$. The flume was provided with a sluice gate at the entry, and the discharge was measured by a triangular weir at the end of the flume. The supercritical depth $y_{1}$ and subcritical sequent depth $y_{2}$ of the jumps were continuously measured using ultrasonic sensors, and the data were saved on a computer and processed by VisiDAQ software. Then, the average of jump depths was computed.

The supercritical approach flow was produced using a sluice gate. The polyethylene sheet was installed in the flume with the reverse bed slope of 0.015 . The hydraulic jump on the reverse bed slope with single screen of the experiments is represented in Fig. 1.

A total of 220 tests were conducted, and the summary of experiments is shown in Table 1. The hydraulic jump was produced in different Froude numbers, and the hydraulic characteristics were measured.

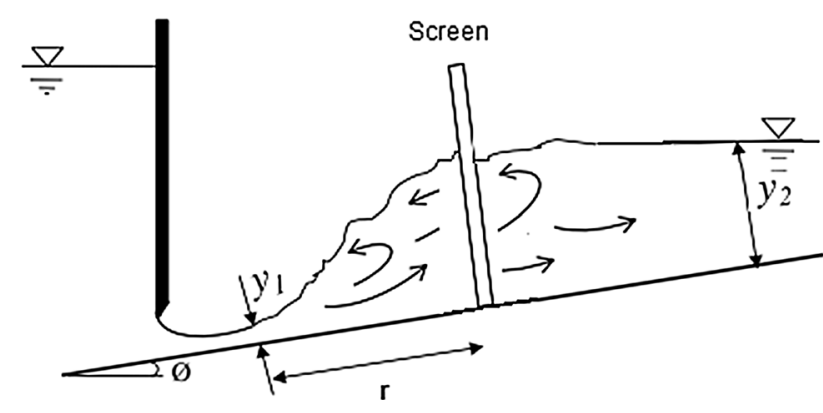

Fig. 1 Forced hydraulic jump on reverse bed slope with single screen
In this study, the water depths were measured at different sections of a jump in the centerline of the flume with a point gauge (accuracy of $0.1 \mathrm{~mm}$ ). The supercritical depth and sequent depth $y_{1}, y_{2}$ were measured as shown in Table 1 . The sequent depth was controlled by an adjustable gate at the end of the channel such that the jumps were formed at the beginning of the reverse bed slope.

\section{Results and discussion}

In order to study a hydraulic jump on a reverse sloped bed, with porous screens or end sill its characteristics in different sections were analyzed.

\section{The depth ratio}

Considering Eq. (4), the sequent depth ratio $y_{2} / y_{1}$ is dependent on the Froude number, the slope of the bed $S_{0}$, the angle of screen $\alpha$, number of the screens, and the height of end sill $S$. The effect of the porous screen on the sequent depth ratio was evaluated by the plot of $y_{2} / y_{1}$ versus $F r_{1}$ in Figs. 2 and 3 for two reverse bed slopes. As seen in these figures, for two bed slope values of 0.015 and 0.025 used in the experiments, sequent depth ratio depends on the Froude number $\left(F r_{1}\right)$. According to Figs. 2 and 3, it can be inferred that by increasing the Froude number the sequent depth ratio $\left(y_{2} / y_{1}\right)$ increases for both single and double screens.

The dimensionless depth deficit parameter, D, was defined by Rajaratnam and Hurtig (2000) as $D=\frac{y_{2}^{*}-y_{2}}{y_{2}^{*}}$, where $y_{2}^{*}$ is the sequent depth of a hydraulic jump on a smooth bed with the same upstream conditions. It is found that, for the hydraulic jump with single screen for two slopes $S_{0}=0.015$ and $S_{0}=0.025$., $D$ varies $0.1-0.4$ and $0.3-0.45$, respectively, that the average values of 0.3 and 0.37 are obtained. These values indicate that the depth ratio formed by single screen is appreciably smaller than depth ratio in the classical hydraulic jump and the depth deficit parameter of hydraulic jump on the reverse bed of 0.025 is greater than slope of 0.015 for the same upstream Froude number.

Figure 3 compares the results of double screens with distances 40-45, 45-50, 50-55, and 55-60 cm. Based on this figure, for screen with distances of 50-55, the sequent depth ratio increases for a given value of the upstream Froude number.

It can be seen that, for the hydraulic jump with double screens in different distances $(40-45,45-50,50-55$ and
Table 1 Summary of experimental parameters

\begin{tabular}{lllllll}
\hline Exp. & $N$ & $R(\mathrm{~cm})$ & $F r_{1}$ & $Y_{1}(\mathrm{~cm})$ & $Q($ lit $/ \mathrm{s})$ & $S_{0}$ \\
\hline A & 1 & $40-45,45-50$, & $4.5-10.6$ & 2.5 & $12-36$ & $0.015,0.025$ \\
& & $50-55,55-60$ & & & & \\
B & 2 & $30,40,50$ & $4.5-10.6$ & 2.5 & $12-36$ & $0.015,0.025$ \\
\hline
\end{tabular}



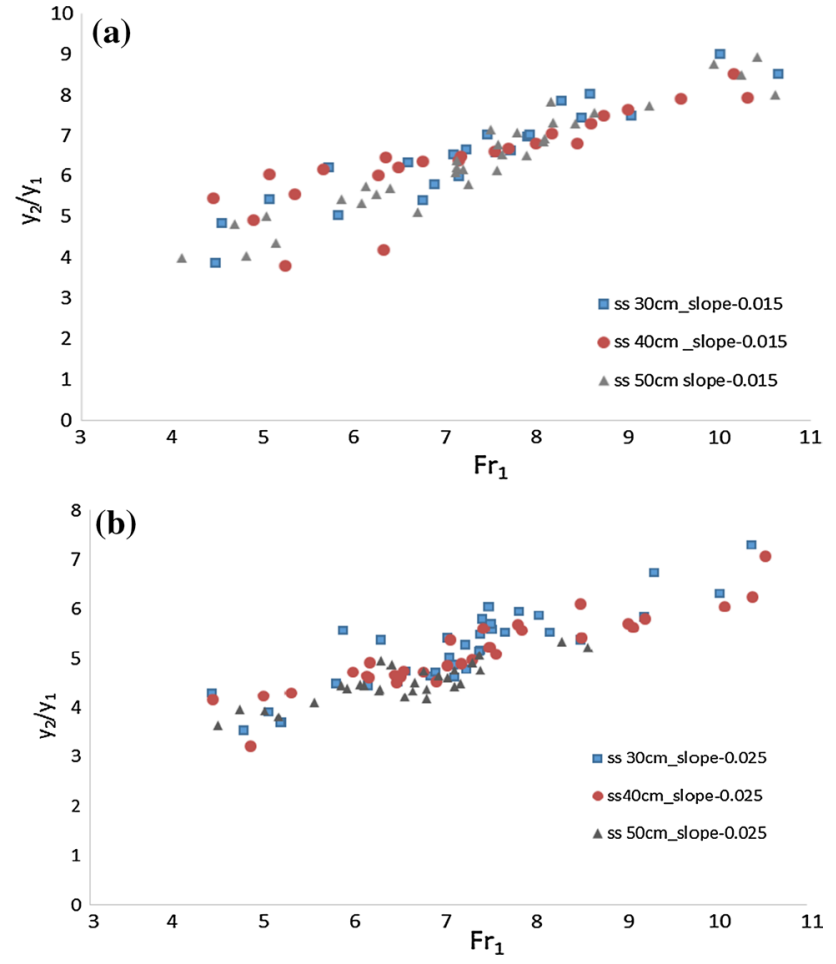

Fig. 2 Sequent depth ratio $y_{2} / y_{1}$ versus $F r_{1}$ on reverse bed slope with single screen with different distances a $S_{0}=0.015$ b $S_{0}=0.025$ )
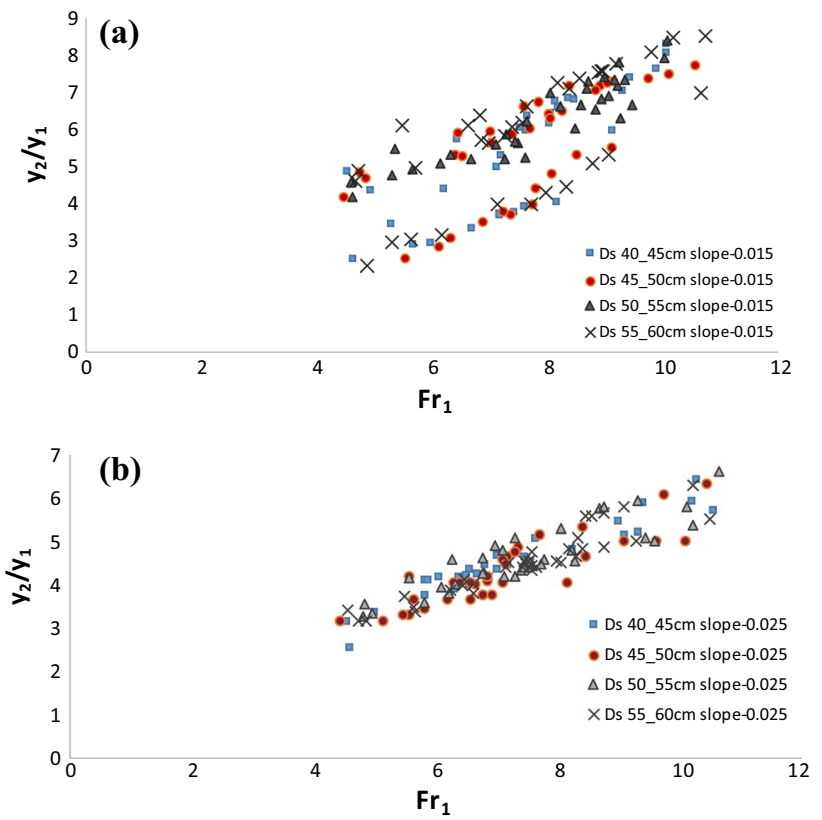

Fig. 3 Sequent depth ratio $y_{2} / y_{1}$ versus $F r_{1}$ on reverse bed slope with double screens with different distances a $S_{0}=0.015$ b $S_{0}=0.025$ )
55-60 cm) for two slopes $S_{0}=0.015$ and $S_{0}=0.025, D$ is constant value of 0.4 .

After a preliminary experimental study, the height of end sill was found $1.5 \mathrm{~cm}$ for Froude number values of 4-10.4. Figure 4 compares the results of sequent depth ratio $\left(y_{2} / y_{1}\right)$ for sill-controlled jump with a height of $1.5 \mathrm{~cm}$ for two slopes of 0.015 and 0.025 . In the reverse bed with a slope of 0.025 , the values of sequent depth ratio $\left(y_{2} / y_{1}\right)$ are about $36 \%$ less comparing with the basin with slope of 0.015 . As the value of the bed slope $S_{0}$ increases, the sequent depth ratio decreases.

\section{The energy dissipation}

The loss of energy in the jump $E_{\mathrm{L}}$ is equal to the difference between the specific energy before and after the jump, $E_{2}-E_{1}$. In Figs. 5 and 6, the relative energy loss, $E_{\mathrm{L}} / E_{1}$, was plotted versus different Froude numbers. It is found that by increasing the Froude number the performance of the screens in dissipating the energy increases for both single and double screens conditions. The increase in the energy loss is reasonable due to higher kinetic energy for high values of Froude number. Comparing the quantity of energy loss due to impact of screen to that one by classical jump (for the same Froude number), it clear that screens contribute to the dissipation of more kinetic energy than the energy dissipated by classical form of hydraulic jump.

In this case, the energy loss on reverse bed slope with single screen for slopes of 0.015 and 0.025 is increased by $13 \%$ and $19 \%$, respectively, compared to classical jump energy. Also the energy loss on reverse bed slope with double screens for two slopes of 0.015 and 0.025 is increased by $18 \%$ and $23 \%$, respectively, compared to classical jump energy.

In the Froude number range in this study, the supercritical flow in collision with double screens creates more energy loss due to the extra turbulences compared to jump behaviors with a single screen. The analysis of results shows that, for each screen distance, the relative energy loss increases with increasing the bed slope.

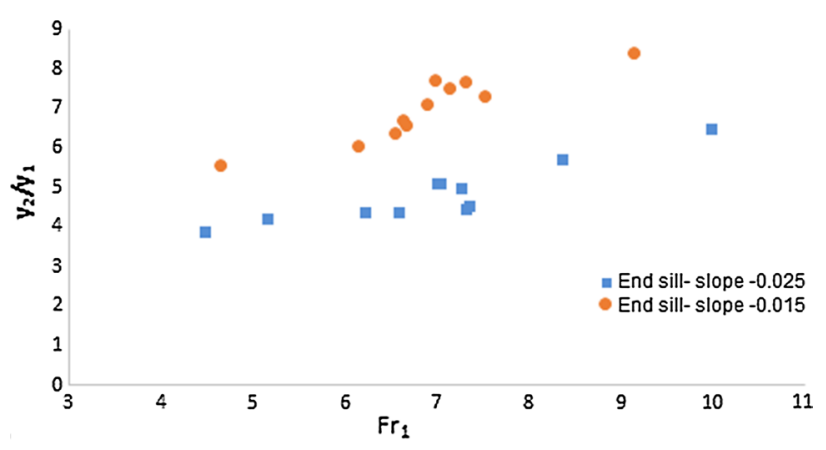

Fig. 4 Sequent depth ratio $y_{2} / y_{1}$ versus $F r_{1}$ for sill-controlled jump on adverse slope for two slopes $S_{0}=0.015$ and $S_{0}=0.025$ 

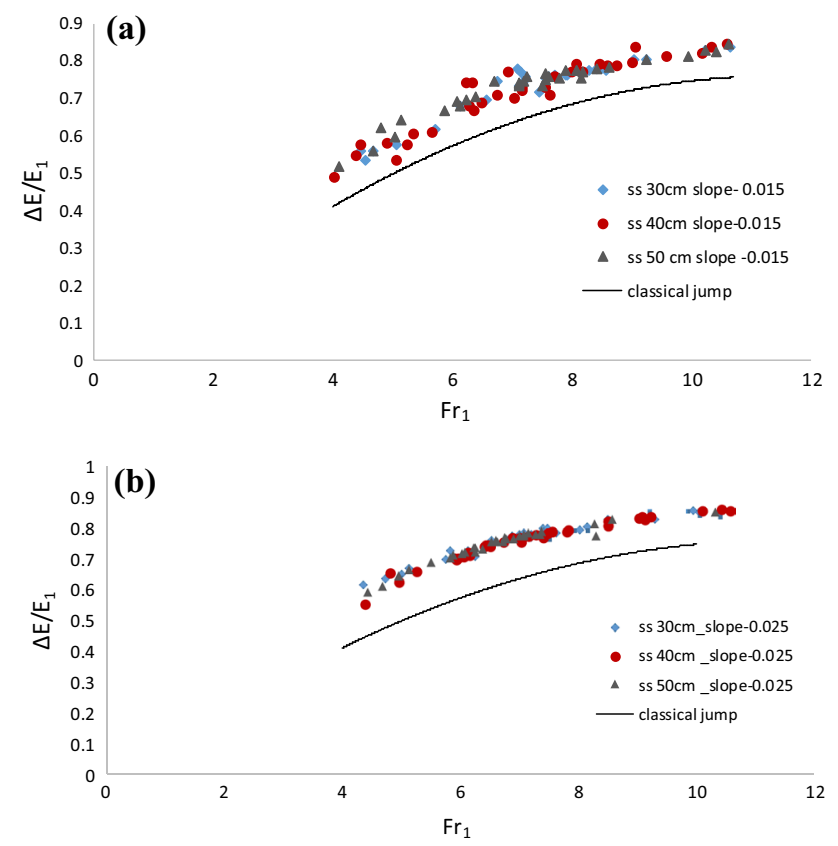

Fig. 5 The relative energy dissipation $E_{\mathrm{L}} / E_{1}$ versus $F r_{1}$ on reverse bed slope with single screen with different distances a $S_{0}=0.015$ b $\left.S_{0}=0.025\right)$
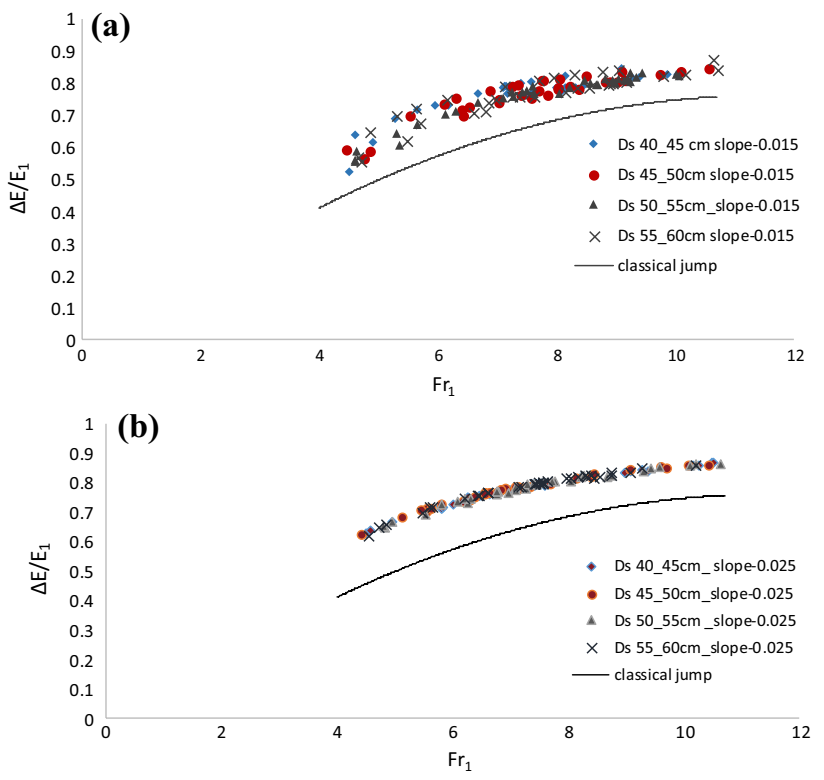

Fig. 6 The relative energy dissipation $E_{\mathrm{L}} / E_{1}$ versus $F r_{1}$ on reverse bed slope with double screens with different distances a $S_{0}=0.015 \mathbf{b}$ $S_{0}=0.025$ )

Figure 7 shows the experimental results of the relative energy loss, as functions of the approach Froude number, $F r_{1}$, for two adverse slopes of 0.015 and 0.025 for sill-controlled jump. Experimental observations showed an increase in the bed angle caused an increase in the relative energy

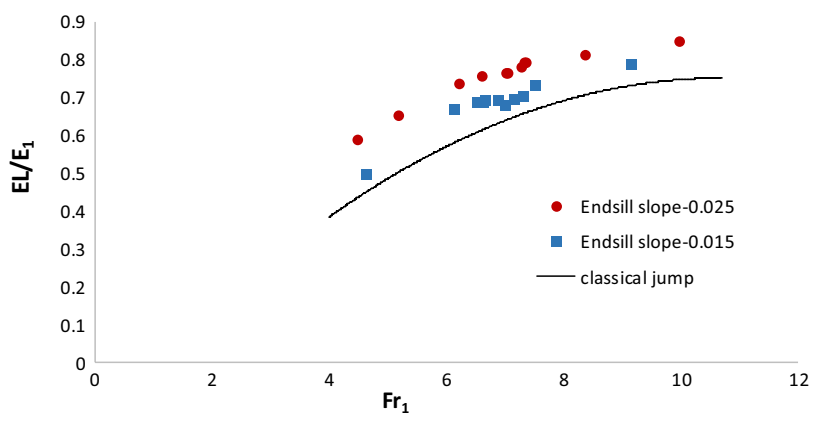

Fig. 7 The relative energy dissipation $E_{\mathrm{L}} / E_{1}$ versus $F r_{1}$ on reverse bed slope sill-controlled jump for two slopes $S_{0}=0.015$ and $S_{0}=0.025$

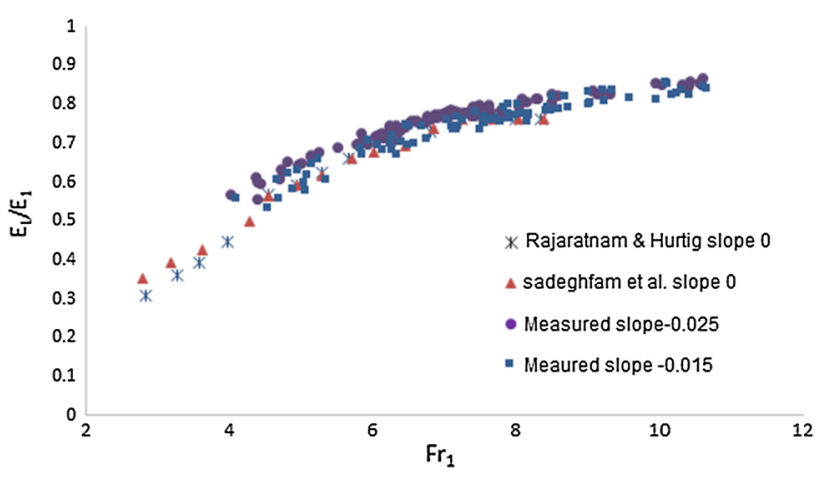

Fig. 8 The comparison of the relative energy dissipation $E_{\mathrm{L}} / E_{1}$ on reverse bed slope with single screen for current and former studies

loss. It can be shown that the energy loss on reverse bed slope sill-controlled jump for two slopes of $S_{0}=0.015$ and $S_{0}=0.025$ is increased approximately $11 \%$ and $17 \%$, respectively, compared to classical jump energy loss.

Figures 8 compares the results of the relative energy for single-screen arrangement with $50 \%$ porosity in adverse bed with slopes of 0.015 and 0.025 and the existing studies. According to this figure, for each adverse bed in the Froude number range of 4-10.6 in the presence of a screen the relative energy loss is more compared to the horizontal bed in studies of Rajaratnam and Hurtig (2000) and Sadeghfam et al. (2014).

Figure 9 also illustrates some comparisons between the existing studies and the results of the double screen arrangement with a porosity of $50 \%$. According to this figure, it is observed that in the adverse slopes of 0.015 and 0.025 the energy dissipation is more compared to the horizontal bed in studies of Rajaratnam and Hurtig (2000) and Sadeghfam et al. (2014).

Figure 10 shows the sequent depth ratio, $y_{2} / y_{1}$, as functions of the approach Froude number, $F r_{1}$, for sill-controlled jump on adverse slope. It can be concluded that an increase in the bed slope results in reduction in the sequent depth compared to the classic jump. 


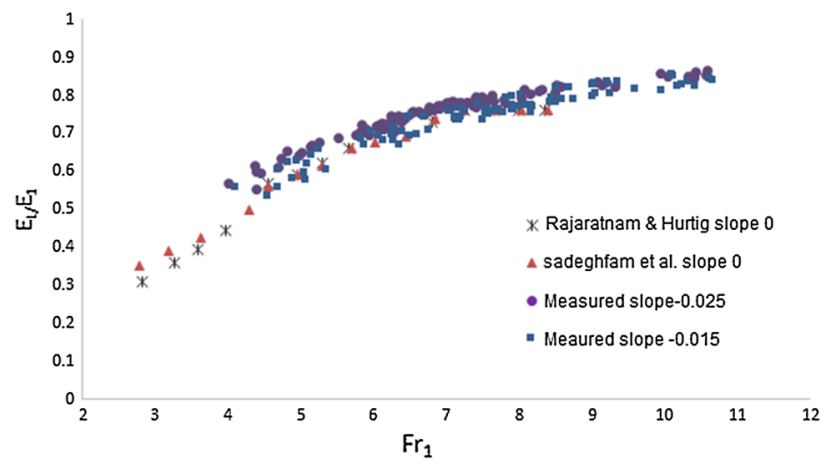

Fig. 9 The comparison of the relative energy dissipation $E_{\mathrm{L}} / E_{1}$ on reverse bed slope with double screens for the current and former studies

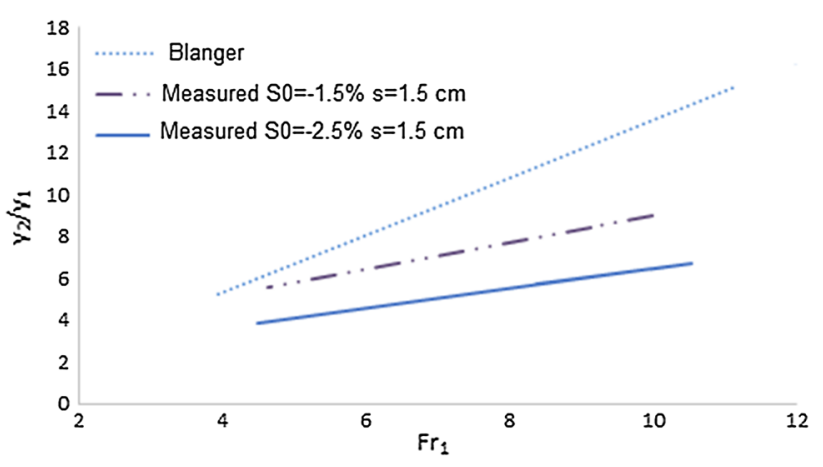

Fig. 10 The comparison of sequent depth ratio $y_{2} / y_{1}$ for sill-controlled jump on adverse slope with the classic hydraulic jump

\section{Conclusions}

In this study, the effect of single and double screens and sillcontrolled hydraulic jump on adverse slopes was investigated from an experimental point of view. The results showed that for a given supercritical depth, $y_{1}$, and Froude number, $F r_{1}$, the tailwater depth of a jump is smaller than that on smooth hydraulic jumps formed on adverse slopes.

1. Due to the instability of such jumps, the results are more scattered compared to the classic hydraulic jump in a horizontal channel. A hydraulic jump on an adverse slope has a complex flow configuration.

2. The presence of a sill stabilizes the jump. In the reverse bed with a slope of 0.025 , the values of sequent depth ratio $\left(y_{2} / y_{1}\right)$ are less compared to slope of 0.015 .

3. Comparison of results shows that the sequent depth reduces with increase in the bed slope for both single and double screens.

4. Results show the relative energy loss produced by screen is greater than that produced by the classical hydraulic jump for the same Froude number, $F r_{1}$, and the double screen dissipates a little more energy than single screen. So the use of screens on reverse bed stilling basin in downstream of the hydraulic structures will be a good alternative to the stilling basins.

5. It should be noted that in an adverse bed stilling basin with the presence of the porous screen, the relative loss of energy increases by increasing the bed slope.

Open Access This article is distributed under the terms of the Creative Commons Attribution 4.0 International License (http://creativeco mmons.org/licenses/by/4.0/), which permits unrestricted use, distribution, and reproduction in any medium, provided you give appropriate credit to the original author(s) and the source, provide a link to the Creative Commons license, and indicate if changes were made.

\section{References}

Behrouzi-Rad R, Fathi-Moghadam M, Ghafouri HR, Alikhani A (2013) Generation of hydraulic jump with sill. Wulfenia J Klagenf 20(2):300-309

Beirami MK, Chamani MR (2006) Hydraulic jumps in sloping channels: sequent depth ratio. J Hydraul Eng 32(10):1061-1068

Beirami MK, Chamani MR (2010) Hydraulic jump in sloping channels: roller length and energy loss Canadian. J Civ Eng 37(4):535-543

Bozkus Z, Aslankara V (2008) Tailwater effect on the energy dissipation through screens. In: Proceedings of the 8th international congress on advances in civil engineering, Eastern Mediterranean University, Famagusta, North Cyprus, ACE

Bozkus Z, Cakir P, Ger M (2007) Energy dissipation by vertically placed screens. Can J Civ Eng 34:557-564

Cherhabil S, Debabeche M (2016) Experimental study of sequent depths ratio of hydraulic jump in sloped trapezoidal channel. In: Hydraulic structures and water system management. 6th IAHR international symposium on hydraulic structures, Portland, 27-30 June, pp 353358. https://doi.org/10.15142/t3610628160853

Farhoudi J, Khalili Shayan H (2013) Theoretical criterion for stability of free hydraulic jump on adverse stilling basins. J Hydraul Struct 1(2):53-66

Minaei Gigloo A, Ghodsian M, Mehraein M (2016) Experimental investigation of hydraulic jump in stilling basin with stepped sill. Modares Civ Eng J 16(1):145-155

Mudgal BV, Pani BS (2012) Drag characteristics of two-dimensional sills in forced hydraulic jumps. J Hydraul Eng 138(5):462-466

Pagliara S, Peruginelli S (2000) Limiting and sill-controlled adverse-slope hydraulic jump. J Hydraul Eng ASCE 126(11):847-851

Parsamehr P, Farsadizadeh D, Hosseinzadeh Dalir A, Abbaspour A, Nasr Esfahani MJ (2017) Characteristics of hydraulic jump on rough bed with adverse slope. ISH J Hydraul Eng 23(3):301-307. https://doi. org/10.1080/09715010.2017.1313143

Rajaratnam N, Hurtig KI (2000) Screen-type energy dissipater for hydraulic structures. J Hydraul Eng 126:310-312

Sadeghfam S, Akhtari AA, Daneshfaraz R, Tayfur G (2014) Experimental investigation of screens as energy dissipaters in submerged hydraulic jump. Turk J Eng Environ Sci 38:126-138. https://doi.org/10.3906/ muh-1401-15

Shaker AJ, Mahdi Salih Y, Herman Abdulgadi M (2013) Performance of screen wall openings shape on energy dissipation. Int J Sci Eng Res 4(11):1538-1544

Singh UK (2018) Experimental study on single and double, screentype energy dissipator for hydraulic structure. http://14.139.251.106:8080/jspui/handle/repository/16261 
Vischer DL, Hager WH (1995) Energy dissipaters: hydraulic structures design manual IAHR. Routledge, Abingdon, p 206
Publisher's Note Springer Nature remains neutral with regard to jurisdictional claims in published maps and institutional affiliations. 